\title{
Wind and wave storms, storm surges and sea level rise along the Estonian coast of the Baltic Sea
}

\author{
Ü. Suursaar ${ }^{1}$, T. Kullas ${ }^{1} \&$ R. Szava-Kovats ${ }^{2}$ \\ ${ }^{1}$ Estonian Marine Institute, University of Tartu, Estonia \\ ${ }^{2}$ Institute of Ecology and Earth Sciences, University of Tartu, Estonia
}

\begin{abstract}
Winter changes in atmospheric circulation above Northern Europe are among the most prominent regional manifestations of global climate change. Particularly vulnerable are the coastal regions along the so-called North Atlantic storm track, along which these changes threaten shipping, infrastructure and human lives. The aim of this paper is to present an overview of storm climatology over the Baltic Sea and to investigate the effects of changes in wind climate on the hydrodynamic regime in the almost tideless fetch-limited nearshore region of West Estonia. The paper presents a statistical analysis of sea level data from tide gauges during 1899-2008, an analysis of wind data from coastal stations during 1966-2007, and a corresponding wave hindcast study. The results show a positive trend both in local storminess and storm surge height. Although both average wind speed and average wave heights showed a slight decrease in the area during 1966-2007, the occurrence of rough sea states has increased. Some of the prominent windstorms also caused major wave storms and storm surges (in 1967, 1969, 2005), depending on cyclone track, coastline configuration and angular distribution of fetches.
\end{abstract}

Keywords: wind climate, storm surges, wave modelling, trends, cyclone tracks.

\section{Introduction}

The concept of a "global sea level trend" and attempts to identify a "climate signal" in sea level rise play a central role in the current climate change research [1]. In addition, other important manifestations of the climate change exist which 
may greatly vary in different parts of the world. For example, shifts in semiglobal or regional atmospheric pressure systems have probably altered cyclone trajectories and wind climate above the North Atlantic [2,3]. Moreover, the impacts of these changes depend largely on orientation and exposure of a specific location.

Estonia lies in the eastern section of the semi-enclosed and nearly tideless Baltic Sea (Fig. 1) where frequent cyclones passing from west to east, whose corresponding variations in wind direction and speed $[3,4]$ create considerable fluctuations in sea level and wave conditions $[5,6]$. Also, as an exposed and windward coast, the area is sensitive to changes in wind conditions and storminess.

The impact of storms, coastal flooding and waves on the coastal zone is frequently severe, and can result in loss of life and extensive damage to property. While more than $95 \%$ of the sea level data remains within -50 and $+60 \mathrm{~cm}$ of the Kronstadt zero benchmark (which approximates the long-term mean sea level for the Estonian coastal sea), a few catastrophically high (up to $275 \mathrm{~cm}$ ) storm surges are on record [4].

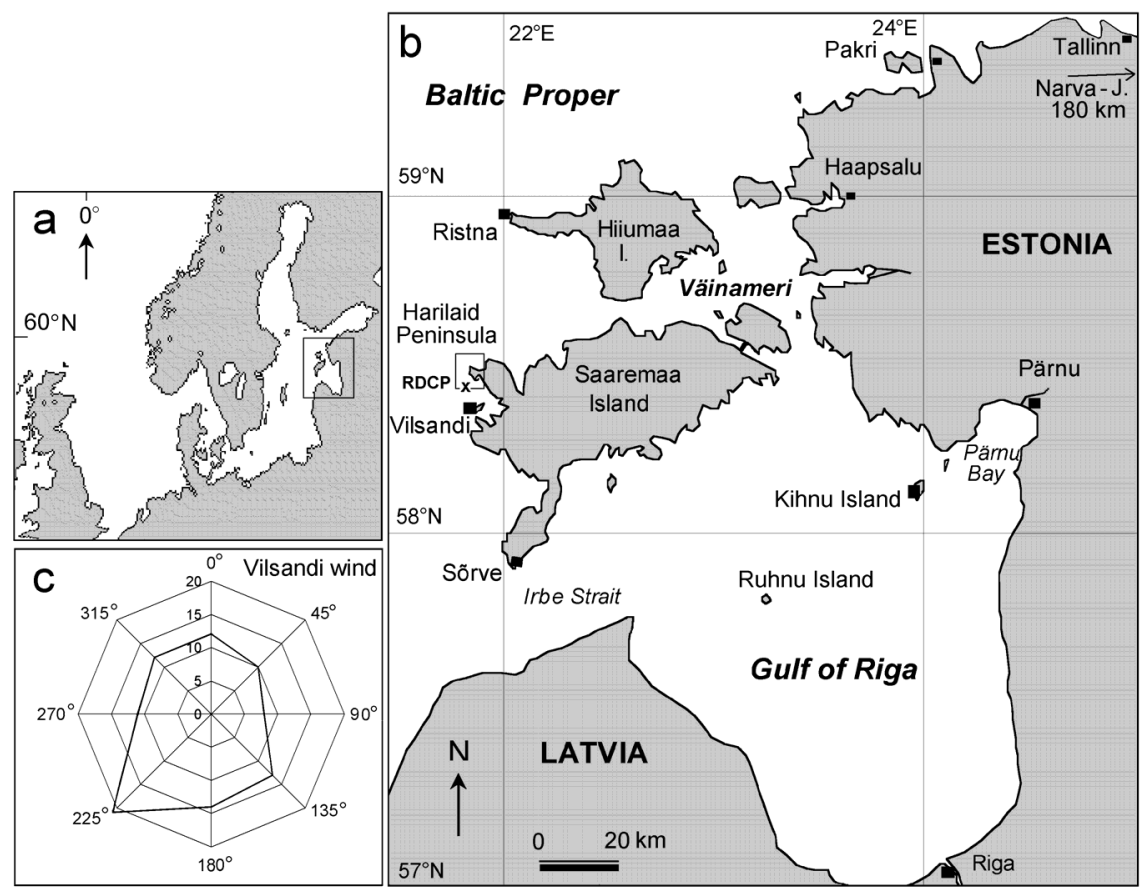

Figure 1: $\quad$ Map of the study area $(a, b)$ with locations of selected tide gauges and weather stations (b). The location of wave hindcast is marked by "RDCP" on (b). The wind rose at Vilsandi station (c) illustrates regional long-term mean wind conditions. 
During extreme windstorms, significant wave height can attain $9.5 \mathrm{~m}$ in the central Baltic Proper off the West-Estonian Archipelago [6]. That said, even shallower storm waves in the Baltic Sea are relatively steep, and thus dangerous to smaller craft. In fact, the sinking of the large passenger ferry Estonia in 1994, which claimed 852 lives, was most likely the result of storm wave damage [7, 8]. Studies of wind- and wave storms, storm surges, and their synchronized occurrences are therefore of significant importance.

The objectives of the paper are (1) to present a statistical analysis of wind data from selected coastal stations and a corresponding wave hindcast, as well as an analysis of mean and extreme sea level data obtained from Estonian tide gauges; (2) to identify the most prominent "combined" storms during 1966-2008 and to analyse their mechanisms of occurrence and statistics.

\section{Material and methods}

\subsection{Meteorological and sea level data}

To study changes in wind climate and local storminess, we used data from meteorological stations at Kihnu $\left(58^{\circ} 05^{\prime} 56^{\prime \prime} \mathrm{N} ; 23^{\circ} 58^{\prime} 15^{\prime \prime} \mathrm{E}\right)$ and Vilsandi $\left(58^{\circ}\right.$ $22^{\prime} 59^{\prime \prime} \mathrm{N}$; $21^{\circ} 48^{\prime} 56^{\prime \prime E}$; Fig. 1b), separated by about $120 \mathrm{~km}$.

Both stations are situated on the windward side of small islands, which allows unobstructed access to the marine wind regimes of the Northern Baltic Proper [9]. Measurements began at Kihnu in 1931, and at Vilsandi in 1865. However, this study is limited to the digitized 10 minutes sustained wind speed data since 1966. Winds have been measured by "weathercocks" (wind vanes of Wild's design) during 1966-1976, automatic anemorhumbometers during 1976-2003, and MILOS-520 automatic weather complexes since September 2003. The older data in the database have been slightly corrected for homogeneity following the procedure described in $[5,10]$.

Data from tide gauges at Pärnu, Ristna and Tallinn were used to ascertain sea level. While most of the twelve tide gauges, currently operated by the Estonian Meteorological and Hydrological Institute (EMHI), are equipped with tide poles and are limited to 2 or 3 measurements per day, these three automatic tide gauges provide hourly data. In Tallinn, the capital city of Estonia, regular sea level measurements started in 1809. A near continuous data set for mean sea level is available since 1842 and for extreme conditions since 1899, although measurements were discontinued in 1996 due to construction work at the Tallinn harbour. Sea level measurements started at Pärnu in 1923, and at Ristna in 1950. We used the updated data on monthly mean and extreme sea levels up to 2008. These data represent relative sea level with regard to the Kronstadt datum and are based, since 1951, on hourly measurements. The monthly values for earlier periods were obtained from daily measurements.

Measurements of local relative sea level are confounded by the influence of isostatic movement, which needs to be removed in order to isolate the climatic component of the sea level rise. Information on land uplift at the studied stations was taken from a map compiled on the basis of precise levelling in 1933-1943, 
1956-1970 and 1977-1985 [11]. The radial crustal movements in Estonia are influenced mainly by regional Fennoscandian postglacial rebound and the uplift along the Estonian coast varies between 0.5 and $2.8 \mathrm{~mm} / \mathrm{yr}$.

\subsection{Wave hindcast}

The wind data from Vilsandi were also used to run a wave model. The hindcast study was preceded by a wave measurement operation at a location near Harilaid Peninsula (Fig. 1b), just 6-7 km north of Vilsandi. An RDCP-600 oceanographic measuring complex from AADI was deployed at a seabed depth of $14 \mathrm{~m}$ between 20 December 2006 and 23 May 2007 [12]. This complex provided calibration data for the SMB model. The SMB-model, also called the significant wave method, is based on the fetch-limited equations of Sverdrup, Munk, and Bretschneider [5,13].

The model calculates the significant wave height $\left(\mathrm{H}_{\mathrm{s}}\right)$, wave period and wavelength for a chosen location under the assumption that wind properties are constant over the entire fetch area. Indeed, strong winds are typically homogeneous in the Baltic Proper [9] and both the reaction and memory time of a large part of the wave fields in this basin are relatively short [6]. During the 5month comparison period, the SMB model reproduced the wave parameters at the single point with acceptable accuracy. The model output required moderate calibration to yield a correlation coefficient as strong as 0.88 , low RMSE (0.23) and nearly equal average and maximum values of calculated and measured wave properties [5].

The calibrated model was further used in multi-year (1966-2007) wave hindcast at a $3 \mathrm{~h}$ interval. An additional comparison of hindcasts for 1996 between the SMB model and $3^{\text {rd }}$ generation WAM model [8] showed that such SMB-type models can be used for site-specific long-term hindcasts, despite their limitations.

\section{Results and discussion}

\subsection{Trends in wind forcing, waves and sea level}

The annual average wind speed shows quasi-periodic 30 to 35 -year cycles and decreasing linear trendline of $0.72 \mathrm{~m} / \mathrm{s}$ over the period 1966-2006 (Fig. 2d). As such, this trend is in contrast to the recent findings of "increasing windiness" and "rising storminess" in Northern Europe [3, 14]. However, the annual maximum wind speed is increasing both at Vilsandi (Fig. 2d) and Kihnu.

Wind data show an increase in storm-hours $(\geq 15 \mathrm{~m} / \mathrm{s})$ by 58 during 1966 2006 and an increase in number of storm days by 6.9 . Our analysis confirms the results of previous studies [3] that the increase in annual maximum wind speeds are attributable to greater increases in winter (December to March). This increase is associated with stronger zonal circulation and higher NAO-index during this time $[14,15]$. 

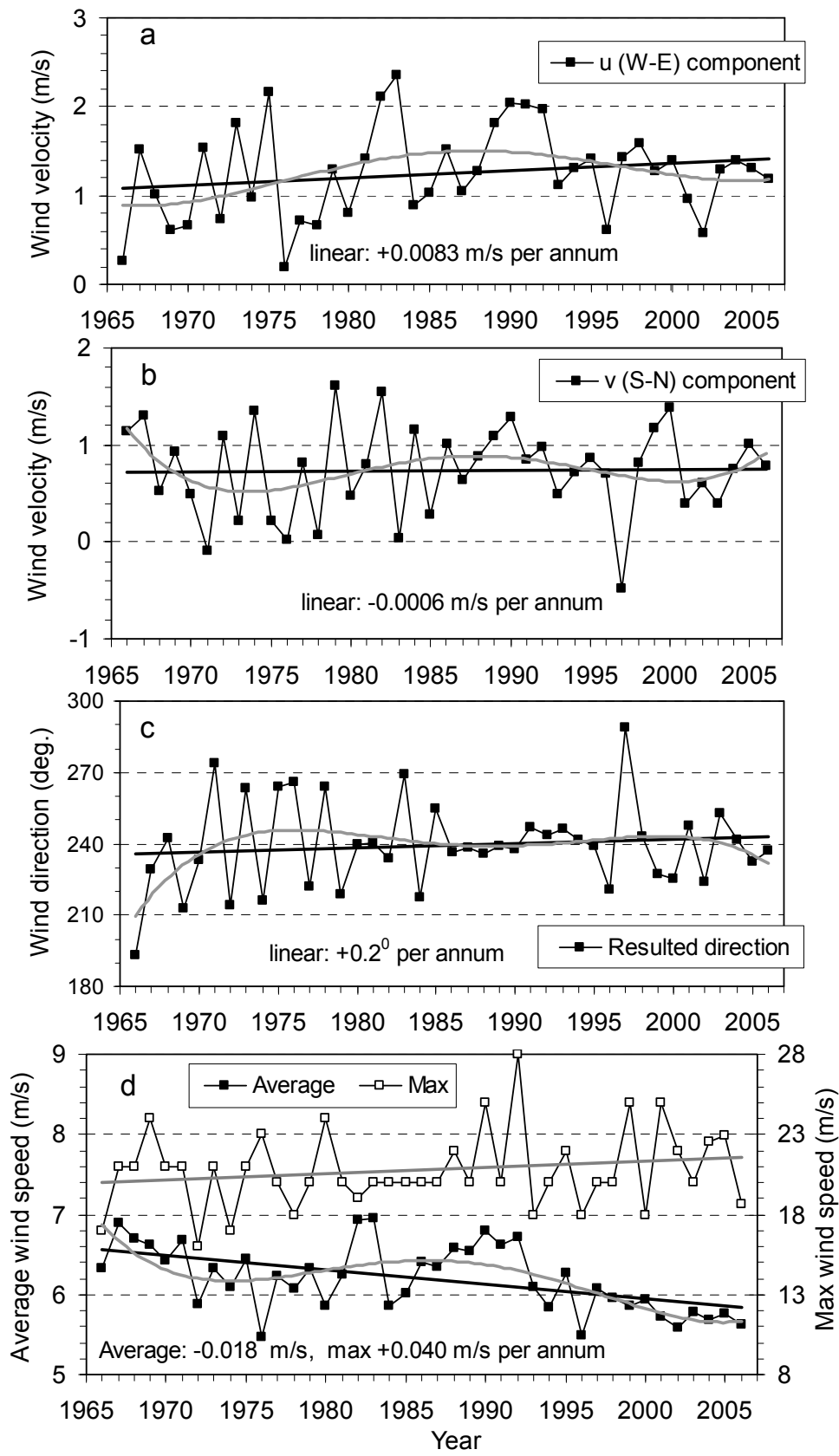

Figure 2: Annual averages of wind velocity components $(a, b)$, wind direction (c), average and maximum wind speed (d) at Vilsandi. Annual changes for each data set are indicated by linear trendlines. 

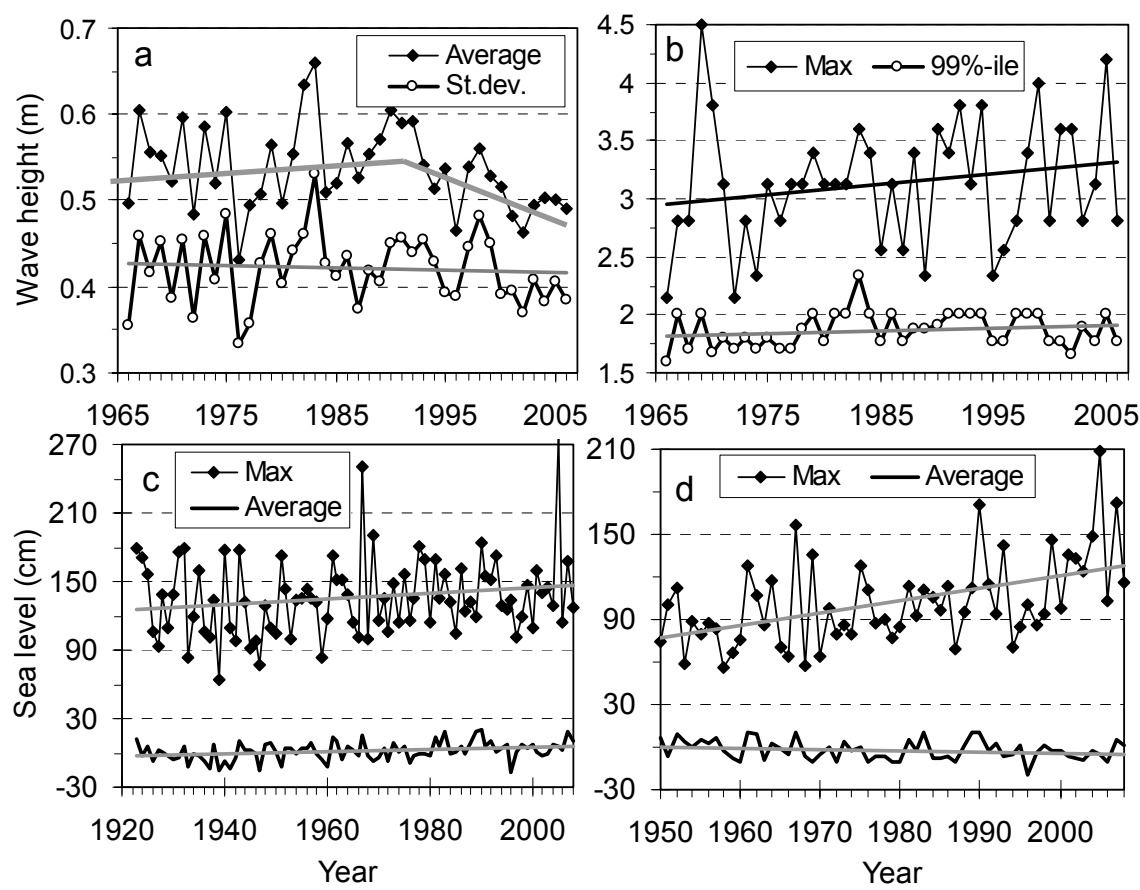

Figure 3: Annual averages and standard deviations (a), 99-percentiles and maximums (b) of annual hindcast wave data at Vilsandi-Harilaid, averages and maximums of sea level at Pärnu (c) and Ristna (d).

While average wind speeds have decreased (Fig. 2d) and the meridional wind velocity component is fairly stable (Fig. 2b), the westerly wind velocity component has clearly increased over the last 40-50 years (Fig. 2a). More precisely, this increase reflects a general decrease in frequency and magnitude of easterly wind events. The increase in $\mathrm{W}$ winds, decreases in $\mathrm{E}$ and $\mathrm{N}$ winds, and shift in annual wind direction (Fig. 2c) imply specific changes to the air-pressure systems, namely, cyclone trajectories over the Baltic Sea [4]. Together with the observed northward shift of the winter storm track $[2,3]$, the number of cyclones passing the Baltic Sea region in winter increased during the second half of the $20^{\text {th }}$ century [16].

Roughly synchronous with wind forcing, mean wave heights and their variability (Fig. 3a) show quasi-periodic cycles with the last high period occurring during 1980-1990 and a slight decrease of $0.001 \mathrm{~m}$ per year during 1966-2006. However, the annual series of the 99-percentiles and annual maxima (Fig. 3b) reveal a clearly increasing trend. Although it may seem intuitive that the wave dynamics are correlated with wind speed, to the $\mathrm{W}-\mathrm{E}$ wind component, and the NAO index, the dynamics are largely attributable to the windward location of the fetch-limited study area. 
The above-described long-term variations in local wind climate and storminess also manifest effects on sea level rise in Estonia (Fig. 3c,d). After adjusting the local relative sea level rise rates to account for isostatic uplift, we calculated sea level rise rates of $1.5 \mathrm{~mm} / \mathrm{yr}$ at Tallinn (1842-1995), $1.7 \mathrm{~mm} / \mathrm{yr}$ at Ristna (1950-2008) and $2.7 \mathrm{~mm} / \mathrm{yr}$ at Pärnu (1924-2008). This is similar to global estimates [15]. However, estimates for annual maximum sea levels are much higher and vary between 4 and $10 \mathrm{~mm} / \mathrm{yr}$ depending on tide gauge location and time interval (Fig. 3d).

Rising sea level trends in annual time series appear to reflect greater rises in winter (December to March) sea level, whereas summer trends are markedly less or even indicate declining sea levels. The significantly greater mean sea level rise in winter correlates with increased local winter storminess and with the greater intensity of westerlies in winter, as indicated by the NAO-index [3, 15].

Storm surges are becoming higher both in Estonia [4] and in Western Europe $[14,17]$. The highest sea level events off the Estonian coast have been registered at Pärnu, where sea level records (Figs. 3c, 5a) identify 30 individual events higher than the critical value of $150 \mathrm{~cm}, 24$ of which occurred between OctoberMarch.

\subsection{Positive relationships and possible sources for inconsistencies}

A number of clear statistical relationships exist among the local wind, sea level and wave data (Fig. 4). Despite the lack of tidal influence, the water volume of the Baltic Sea experiences both seasonal and meteorologically forced (synoptical) variations, which result in considerable variation in sea level (Fig. 4ab).

Due to limited water exchange capacity through the Danish Straits, these variations are slow. Weeks or even months of stable wind conditions are required to create significant changes in water volume. For example, in December 2004 and January 2005, a series of strong west-cyclones gradually elevated the background sea level about $70 \mathrm{~cm}$ over the long-term mean. Subsequently, the 2 -meter high local storm surge by hurricane Gudrun resulted in a record $275-\mathrm{cm}$ sea level at Pärnu [4]. In contrast, the average sea level in spring and summer can fall about $50 \mathrm{~cm}$ below average (Fig. 4ab).

Although wave conditions are affected directly by winds (Figs. 3ab, 4), their relationship is not always straightforward owing to the fetch-limited study area. The longest effective fetches lie in W-NW directions. On the other hand, E, N, or even S-SW winds cannot yield very rough seas at the study location, regardless of strength. However, the share of remotely generated wave fields for SW winds (swell) can be substantial [8].

\subsection{Identification of the most significant storms during 1966-2008}

The most destructive storms in windward Estonia usually occur as combined wind- and wave storms, also accompanied by storm surges. These are mainly associated with so-called European or severe cyclonic storms. 
156 Management of Natural Resources, Sustainable Development and Ecological Hazards II
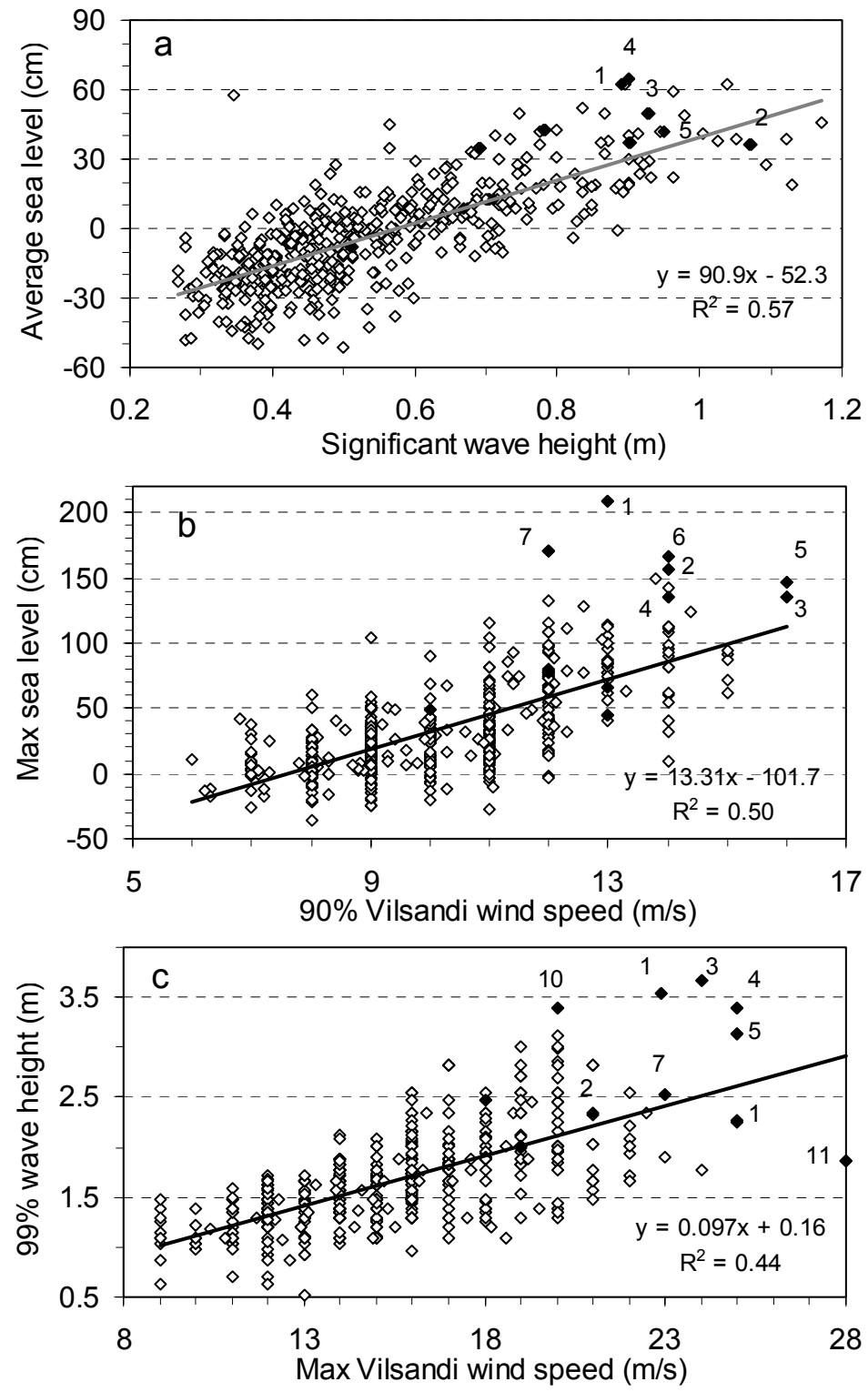

Figure 4: Relationships between monthly samples of significant wave height and Ristna sea level (a), 90-percentiles of Vilsandi wind speed and Ristna maximum sea level (b), and maximum wind speeds at Vilsandi and 99-percentiles of wave heights near Harilaid Peninsula (c). Eleven prominent storms (Table 1) are shown with black symbol. 
Table 1: The most significant storms during 1966-2008 ranked according to the combined values of $10 \mathrm{~min}$ sustained wind speeds at the two meteorological stations, maximum sea levels at Pärnu and Ristna, and wave heights off Harilaid-Vilsandi (90 and 99-percentiles of monthly data samples, comprising hindcast results with $3 \mathrm{~h}$ interval). *- possible underestimation due to failure of wind equipment during the storm.

\begin{tabular}{|l|c|cc|cc|cc|}
\hline Date & Rank & \multicolumn{2}{|c|}{ Max wind } & \multicolumn{2}{|c|}{ Max sea level } & \multicolumn{2}{c|}{ Wave height } \\
& & \multicolumn{2}{|c|}{ Vilsandi Kihnu } & Pärnu Ristna & $90 \%$ & $99 \%$ \\
\hline 18 Oct 1967 & 2 & 21 & 29 & 250 & 157 & 1.77 & 2.33 \\
\hline 2 Nov 1969 & 3 & 24 & 24 & 191 & 135 & 1.66 & 3.66 \\
\hline 12 Sept 1978 & 9 & 18 & 22 & 181 & 77 & 1.57 & 2.47 \\
\hline 21 Nov 1980 & 8 & 19 & 28 & 170 & 66 & 1.40 & 2.00 \\
\hline 22 Feb 1990 & 6 & 25 & 19 & 184 & 166 & 1.45 & 2.26 \\
\hline 13 March 1992 & 11 & 28 & 16 & 85 & 45 & 1.28 & 1.86 \\
\hline 29 July 1992 & 10 & 20 & 18 & 125 & 49 & 0.87 & 3.40 \\
\hline 17 Dec 1999 & 5 & 25 & 24 & 147 & 146 & 1.67 & 3.13 \\
\hline 1 Nov 2001 & 4 & 25 & 24 & 159 & 135 & 1.77 & 3.40 \\
\hline 9 Jan 2005 & 1 & $23 *$ & 25 & 275 & 209 & 1.77 & 3.54 \\
\hline 14 Jan 2007 & 7 & 23 & 19 & 168 & 171 & 1.50 & 2.52 \\
\hline
\end{tabular}

We identified about 30 strongest storms distinguishable by at least one of the studied parameters during 1966-2008, and ranked them by joint magnitude of maximum wind speed, sea level and wave height (each factor having equal weight). Table 1 shows the top eleven. These storms include the most notorious hurricane Gudrun in 2005, which inundated the city of Pärnu about $1 \mathrm{~km}$ landwards. The next strongest storms occurred in 1967, 1969, 2001 ("Janika"), and 1999 ("Anatol"). The list does not include the 6-7 August 1967 storm, which featured very strong N-NW winds, but no storm surges.

Sea levels attaining 150-170 over the mean cause inundation of cities such as Pärnu and Haapsalu, which are located at the heads of shallow and narrow bays exposed to SW and W. Due to their specific morphometric features, these bays probably have large amplification (Green's) factor for surge waves. While empirical return periods of both maximum wind speeds and wave heights (Fig. 5b,c) can be satisfactorily fitted and predicted using theoretical (e.g. Gumbel-type) distributions, a few surge events can act as outliers from the theoretical distributions (Fig. 5a). Therefore, the occurrence statistics of the most extreme sea levels are scarcely predictable by means of return statistics in such specific locations and should instead be modelled dynamically [4].

All the listed storms-storm surges occurred because the centre of the powerful and fast moving cyclones bypassed Estonia to the north over the Scandinavian Peninsula and Bothnian Sea (i.e., tracks between SW1 and W1 in Fig. 6). As a rule, the strongest winds occur a few hundreds kilometres righthand from the cyclone track (local wind speed appears as a vector sum of winds within the baric system itself due to the pressure gradient, and travelling velocity 


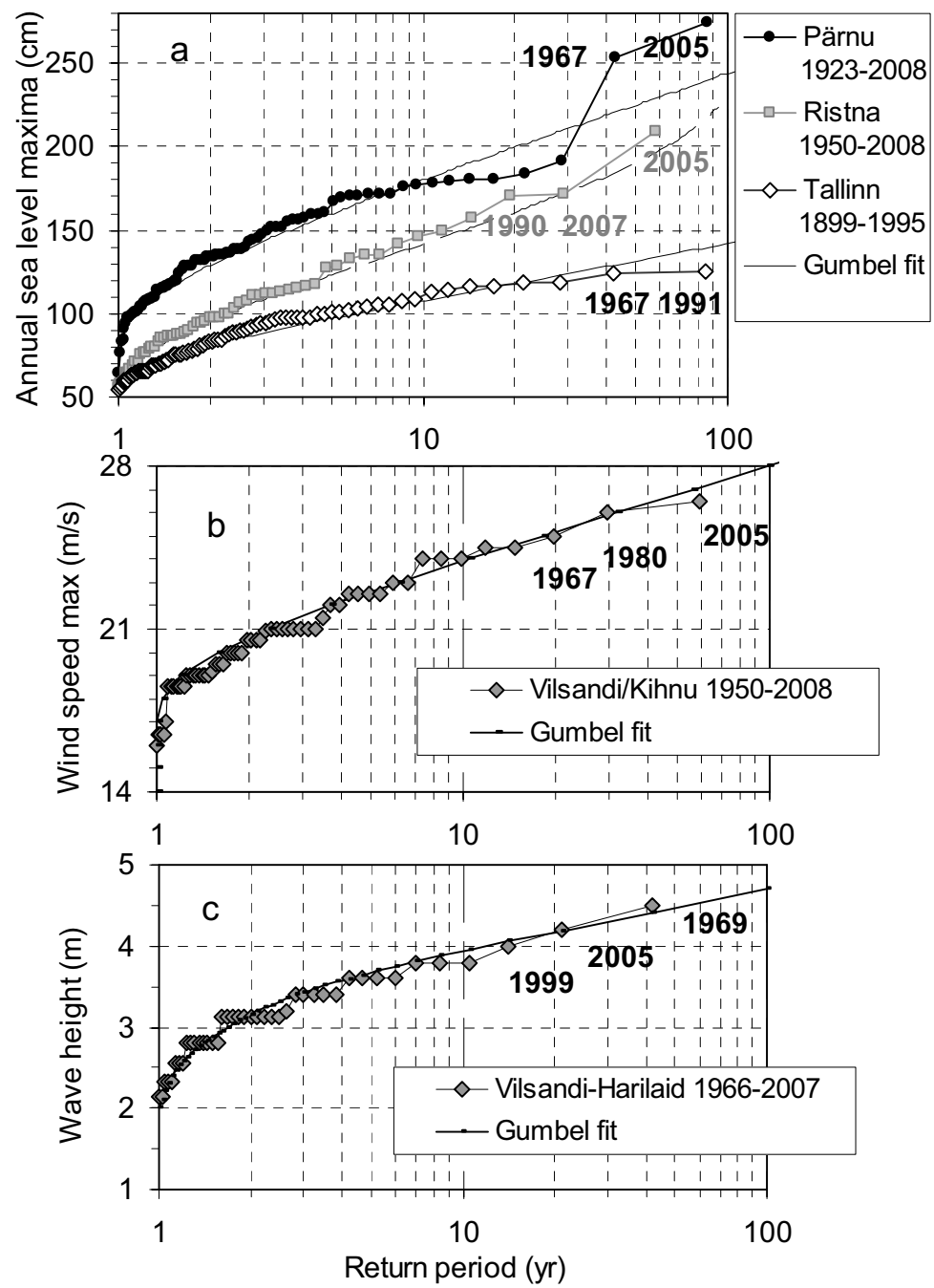

Figure 5: Return periods based on annual maximum data: sea level at Pärnu, Ristna and Tallinn (a), sustained wind speed at Vilsandi and Kihnu (averages of two stations, b), and hindcasted wave height off the Harilaid (c). The empirical curves are shown with Gumbel distribution curves (corresponding mode and scale parameters calculated using least-squares method).

of the baric system relative to land), and reduced friction above the sea surface and the elongated shape of the Baltic Sea allows strong unobstructed winds to land along West Estonia [4, 9]. 


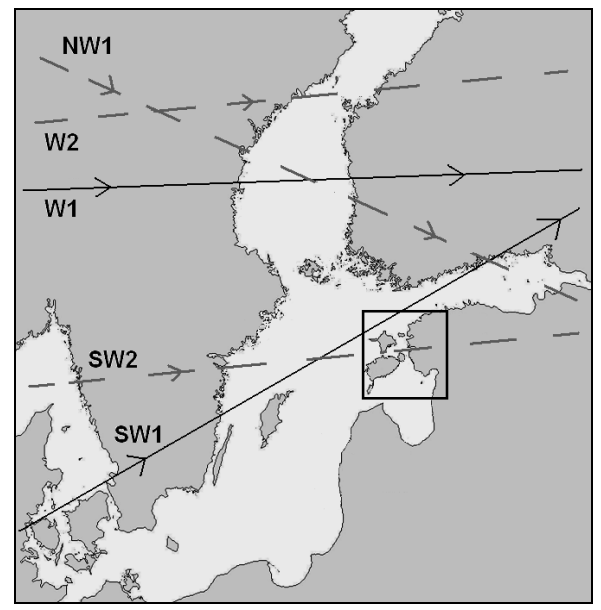

Figure 6: Cyclone trajectories yielding the strongest combined wind/ wave/ storm surges roughly fall between tracks SW1 and W1. Less influential storms follow tracks SW2, W2 and NW1.

\section{Conclusions}

Although the mean properties of wind speed and wave heights were fairly stable (and the adjusted local mean sea level rise of $1.5-2.7 \mathrm{~mm} / \mathrm{yr}$ approximates global estimates), the extreme statistics of these parameters all show significant increases over the last half-century in Estonia. Especially in winter, the share of easterly winds has decreased and westerly winds - including strong winds - have increased. As an exposed and windward coast, the studied area is sensitive to changes in cyclone trajectory and shifts in semi-global atmospheric pressure centres above North Atlantic, whose exact mechanisms and further perspectives are still unclear. A search for the strongest combined storms revealed that some windstorms (but necessarily not all) have caused major wave storms and storm surges (in 1967, 1969, 2005), depending on cyclone track, coastline configuration and angular distribution of fetches.

\section{Acknowledgements}

The study was supported by Estonian Science Foundation grants No. 7609 and 7564, and target financed theme SF0180104s08.

\section{References}

[1] Smith, D., Raper, S.B., Zerbini S. \& Sanchez-Arcilla, A., (eds.), EUR 19337 - Sea level change and coastal processes - implications for Europe. Office for Official Publications of the European Communities: Luxembourg, 247 pp., 2000. 
[2] Ulbrich, U. \& Christoph, M., A shift of the NAO and increasing storm track activity over Europe due to anthropogenic greenhouse gas forcing. Climate Dynamics, 15, pp. 551-559, 1999.

[3] Jaagus, J., Post, P. \& Tomingas, O., Changes in storminess on the western coast of Estonia in relation to large-scale atmospheric circulation. Climate Research, 36, pp. 29-40, 2008.

[4] Suursaar, Ü., Kullas, T., Otsmann, M., Saaremäe, I., Kuik, J. \& Merilain, M., Cyclone Gudrun in January 2005 and modelling its hydrodynamic consequences in the Estonian coastal waters. Boreal Environment Research, 11, pp. 143-159, 2006.

[5] Suursaar, Ü. \& Kullas, T., Decadal variations in wave heights off Cape Kelba, Saaremaa Island, and their relationships with changes in wind climate. Oceanologia, 51, pp. 39-61, 2009.

[6] Broman, B., Hammarklint, T., Rannat, K., Soomere, T. \& Valdmann, A., Trends and extremes of wave fields in the northern part of the Baltic Proper. Oceanologia, 48 (s), pp. 165-184, 2006.

[7] Karppinen, T. \& Ling, N., Estonia: hard facts and realities. The Naval Architect, September, pp. 9-18, 1998.

[8] Räämet, A., Suursaar, Ü., Kullas, T. \& Soomere, T., Reconsidering uncertainties of wave conditions in the coastal areas of the northern Baltic Sea. Journal of Coastal Research, SI 56, pp. 257-261, 2009.

[9] Soomere, T., Extreme wind speeds and spatially uniform wind events in the Baltic Proper. Proc. Estonian Acad. Sci. Eng., 7, pp. 195-211, 2001.

[10] Scientific-practical handbook of the climate of the USSR 1990, Part 3, Gidrometeoizdat, Leningrad, (in Russian).

[11] Vallner, L., Sildvee, H. \& Torim, A., Recent crustal movements in Estonia. Journal of Geodynamics, 9, pp. 215-223, 1988.

[12] Suursaar, Ü., Jaagus, J., Kont, A., Rivis, R. \& Tõnisson H., Field observations on hydrodynamic and coastal geomorphic processes off Harilaid Peninsula (Baltic Sea) in winter and spring 2006-2007. Estuarine Coastal and Shelf Science, 80, pp. 31-41, 2008.

[13] Seymour, R.J., Estimating wave generation in restricted fetches. J. ASME WW2, May 1977, pp. 251-263, 1977.

[14] Alexandersson, H., Schmidt, T., Iden, K. \& Tuomenvirta, H., Long-term variations of the storm climate over NW Europe. The Global Atmos. Ocean. Syst., 6, pp. 97-120, 1998.

[15] Wakelin, S.L., Woodworth, P.L., Flather, R.A. \& Williams, J.A., Sealevel dependence on the NAO over the NW European Continental Shelf. Geophys. Res. Lett., 30, Art. No. 1403, 2003.

[16] Sepp, M., Post, P. \& Jaagus, J., Long-term changes in the frequency of cyclones and their trajectories in Central and Northern Europe. Nordic Hydrology, 36, pp. 297-309, 2002.

[17] Lowe, J.A., Gregory, J.M. \& Flather, R.A., Changes in the occurrence of storm surges around the United Kingdom under a future climate scenario using dynamic storm surge model driven by the Hadley Centre climate models. Climate Dynamics, 18, pp. 179-188, 2001. 